\title{
Corrosion and Micro-abrasive Wear Behaviour of 2524-T3 Aluminium Alloy with PAni-NPs/PSS LbL Coating
}

\author{
Uriel Darhê Oudinot Dias Rangel ${ }^{a}$, Roger Borges ${ }^{b}$, Danilo Alves Oliveira ${ }^{a}$,
}

\author{
Larissa Solano de Almeida ${ }^{c}$, Rogério Valentim Gelamo ${ }^{\text {, José Roberto Siqueira Júnior }}$,
}

\section{Luciana Sgarbi Rossino ${ }^{c, e}$, Jéferson Aparecido Moreto ${ }^{a} *$ (D)}

\begin{abstract}
${ }^{a}$ Instituto de Ciências Exatas, Naturais e Educação, Universidade Federal do Triângulo Mineiro UFTM, Av. Doutor Randolfo Borges Júnior, Univerdecidade, CEP 38.064-200, Uberaba, MG, Brasil ${ }^{b}$ Departmento de Química, Universidade Federal do Paraná, CEP 81.531-980, Curitiba, PR, Brasil ${ }^{c}$ Faculdade de Tecnologia de Sorocaba - FATEC, Av. Engenheiro Carlos Reinaldo Mendes, 2015, Alto da Boa Vista, CEP 18.013-280, Sorocaba, SP, Brasil

'Instituto de Ciências Tecnológicas e Exatas, Universidade Federal do Triângulo Mineiro - UFTM. Av. Doutor Randolfo Borges Júnior, Univerdecidade, CEP 38.064-200, Uberaba, MG, Brasil

${ }^{e}$ Universidade Federal de São Carlos - UFSCar, Rodovia João Leme dos Santos, Km 110, Bairro do Itinga, CEP 18.052-780, Sorocaba, SP, Brasil
\end{abstract}

Received: August 28, 2018; Revised: February 25, 2019; Accepted: April 16, 2019

In this paper, we present an alternative method to obtain thin films for coating protection on the surface of the AA2524-T3 Al-alloy by using the Layer-by-Layer (LbL) technique. The LbL films were fabricated by alternated immersion of the Al-alloy into a poly(styrene sulfonate) (PSS) and polyaniline nanoparticles (PAni-NPs) solutions, obtaining a PAni-NPs/PSS bilayer architecture. The LbL films were characterized by ultraviolet-visible spectroscopy (UV-Vis), Fourier-transform infrared spectroscopy (FTIR), atomic force microscopy (AFM), electrochemical and micro-abrasive wear tests. The results show that the number of bilayers promotes shifts to less negative potentials, indicating an optimized system, in which the best performance was observed for a 15-bilayer PAni/PSS LbL film. The pitting potential $\left(\mathrm{E}_{\mathrm{pit}}\right)$ values shifted $130 \mathrm{mV}$ (from $-610 \mathrm{mV}$ to $-480 \mathrm{mV}$ ) in comparing a bare Al-alloy. The predominantly wear mechanism for AA2524-T3 with PAni-NPs/PSS bilayers was scratching whereas for the bare material there was an equivalence between scratching and rolling mechanisms. The results proved that the incorporation of PAni-NPS by the LbL method may be propitious as protective coating against corrosion in AA2524-T3 alloy.

Keywords: $2 X X X$ series aluminium alloys, LbL technique, PAni nanoparticles, micro abrasive wear tests, aircraft fabrication.

\section{Introduction}

Nowadays, great attention has been given to the study of aluminium and its alloys since its applications include civil construction, energy transportation, aeronautic and automotive industry ${ }^{1-5}$. As reported by Costenaro et al ${ }^{6}$, aluminium alloys from the $2 \mathrm{xxx}$ series are very favorable for aircraft applications due to their low density, high mechanical resistance and durability. However, aluminium alloys present a high amount of intermetallics (IMs) leading to an increase of localised corrosion ${ }^{7,8}$. The IMs are formed during alloy solidification and their size and number in the metal matrix depend on several factors such as impurity content, chemical composition and the solid solution solubility ${ }^{9}$. Thus, in order to improve the durability of the aircrafts, the aeronautical industry has been constantly working on development of new advantageous aluminium alloys ${ }^{10}$.

*e-mail: jeferson.moreto@uftm.edu.br
The AA2524-T3 (Solution Heat Treated and Cold Worked) alloy produced by ALCOA may be used as fuselage skin material and represents a potential replacement for the AA2024 alloy, widely used by the aircraft industry ${ }^{11-15}$. Recent studies ${ }^{11,14,10}$ have shown that the fatigue behaviour of the AA2524-T3 alloy depends on experimental conditions (eg, applied stress, loading rate, environment as well as the crystalline orientation of the sample). With regarding to the electrochemical tests, it was possible to verify that the corrosion potential $\left(\mathrm{E}_{\text {corr }}\right)$ and the pit nucleation potential $\left(\mathrm{E}_{\mathrm{pit}}\right)$ values are quite similar and the variation in the ratio of passive/active areas and/or cathode/anode, which may be related to the presence of different types of IMs ${ }^{12,15}$. Studies developed by Birbilis et al ${ }^{16,17}$ confirm that the electrochemical characteristics of IMs vary significantly in terms of corrosion potential $\left(\mathrm{E}_{\text {corr }}\right)$, disintegration, reduction of oxygen and dissolution reactions. Other work in the literature ${ }^{18-21}$ describes the galvanic coupling between the IM particles and the aluminium matrix. In this way, the use of protective coatings appears as a possible alternative 
against the advancement of the corrosion process of the AA2524-T3 alloy.

In this context, chromatization is the most effective conversion coating for Al-alloys ${ }^{22}$. However, the tailings from the treatment process are highly toxic, which makes their use unfeasible ${ }^{22}$. Several reports have shown that conductive polymers can be useful in corrosion protection as a form of coating onto metals and metal alloys by using electrochemical deposition techniques ${ }^{5,23-24}$. Fang et al ${ }^{25}$ and Cao et al ${ }^{26}$ reported that polyaniline (PAni) conducting polymer is attractive due to their stability, tunable conductivity, controllable structure, ease of synthesis as well as protective coating or as corrosion inhibitors. Moreover, mostly of the studies involving the formation of PAni films on the surface of metallic materials were obtained by using electrodeposition techniques. Gomes et al ${ }^{27}$ studied the influence of multilayer coating using layer-by-layer ( $\mathrm{LbL}$ ) method on the corrosion behaviour of 2024-T3 aluminium alloy and verified by potentiodynamic polarization, chronoamperometry and electrochemical impedance spectroscopy (EIS) techniques an increase of corrosion resistance in the chloride containing environment for the surface coated with 08 (Poly (vinylsulfonic acid, sodium salt/PAni) bilayer. To date, polymer coatings obtained via the LbL self-assembly technology are scarce in aluminium alloys used by aircraft materials, evidencing the need for new studies.

Here, we present an alternative deposition method to obtain thin films on the surface of the AA2524-T3 Al-alloy by using the $\mathrm{LbL}$ technique as a potential substitute of traditional techniques as chromium conversion coatings (CCCs) and electropolymerization (EP) for instance. The LbL technique is a pervasive method for fabricating ultrathin coating in polymers, colloids and biomolecules substrate ${ }^{28}$. The films of PAni-NPs/PSS coated on the surface of AA2524-T3 alloy were characterized by using ultraviolet-visible spectroscopy (UV-Vis), Fourier-transform infrared spectroscopy (FTIR), atomic force microscopy (AFM), scanning electron microscopy (SEM), energy-dispersive X-ray spectroscopy (EDX), open circuit potential (OCP), potentiodynamic polarization curves (PPc) and micro-abrasive wear tests (MAWTs).

\section{Experimental}

\subsection{AA2524-T3 aluminium alloy}

The alloy used was a $1.2 \mathrm{~mm}$-thick $2524-\mathrm{T} 3 \mathrm{Al}$ plate with nominal composition (\%w.t) of $3.84 \% \mathrm{Cu}, 0.04 \% \mathrm{Si}$, $0.06 \% \mathrm{Fe}, 1.31 \% \mathrm{Mg}, 0.56 \% \mathrm{Mn}, 0.029 \% \mathrm{Ti}, 0.01 \% \mathrm{Zn}$ with the made up of Al. Further information regarding the chemical composition of the AA2524-T3 alloy can be found in ${ }^{12}$.

\subsection{Preparation of Polyaniline Nanoparticles (PAni-NPs)}

PAni-NPs were prepared according to the procedure described by Cao et al ${ }^{29}$. First, $2 \mathrm{~mL}$ of aniline hydrochloride solution (93.1 $\mathrm{g} \mathrm{mol}^{-1}$ and density of $0.9 \mathrm{~g} \mathrm{~cm}^{-3}$ ) were dissolved in $200 \mathrm{~mL}$ of deionized water previously mixture with chlorhydric acid (36.5 $\left.\mathrm{g} \mathrm{mol}^{-1}-37 \%\right)$. The solution was slowly stirred until a homogenous mixture was obtained. In a second part, $1.6 \mathrm{~g}$ of ammonium peroxydisulfate $\left(\mathrm{NH}_{4} \mathrm{~S}_{2} \mathrm{O}_{8}\right)$ was dissolved in $200 \mathrm{~mL}$ of deionized water. The aniline hydrochloride solution was maintained in an ice bath with ammonium persulphate solution in 1:1 proportion. This new solution was stirred at $4^{\circ} \mathrm{C}$ for $24 \mathrm{~h}$ and filtered. The resulting material was washed exhaustively and dried in vacuum. The dried powder obtained (PAni) was agitated in an ultrasound bath (dispersed in propanol) during $2 \mathrm{~h}$ in order to obtain PAni-NPs.

\subsection{Fabrication and characterization of the $L b L$ film}

Prior obtaining thin film, the surfaces of the AA2524-T3 Al-alloy were ground with $\mathrm{SiC}$ abrasive paper to 2400 \#, degreased with acetone, rinsed exhaustively with deionized water and dried using nitrogen jet. The coating was built up atop the 2524-T3 alloy surface by using the layer-bylayer (LbL) technique. Firstly, the AA2524-T3 alloy was dipped for $3 \mathrm{~min}$ in the $\mathrm{H}_{2} \mathrm{SO}_{4}+\mathrm{H}_{2} \mathrm{O}_{2}$ solution (3:1) and then washed with water. The LbL films were fabricated by alternated immersion of the AA2524-T3 alloy into a PAni and poly(styrene sulfonate) (PSS) solutions, obtaining a PAni-NPs/PSS bilayer architecture. The repetition of this process permitted to prepare films in a multilayer fashion with $1,5,10,15$ and 20 bilayers.

The film growth was monitored by ultravioletvisible spectrophotometry (UV-Vis) by using an Avantes AvaSpec-2048 fiber optic spectrometer and the topography of the film was investigated by atomic force microscopy (AFM) using a SPM-9700 Shimadzu in dynamic mode at room temperature. Fourier transform infrared spectroscopy (FTIR) was performed to analyze the chemical bonds and interactions between PAni-NPs/PSS in the film formed on the surface of the AA2524-T3 Al-alloy using an Agilent Cary 600 Series FTIR Spectrometer. It is important to mention that PAni-NPs/PSS LbL films were fabricated onto indium-tinoxide (ITO)-coated glass substrates (used as blank) for the UV-Vis analysis. A schematic representation of PAni-NPs/ PSS LbL films architecture and a digital image of the films prepared with different bilayers is illustrated in Figure 1. 


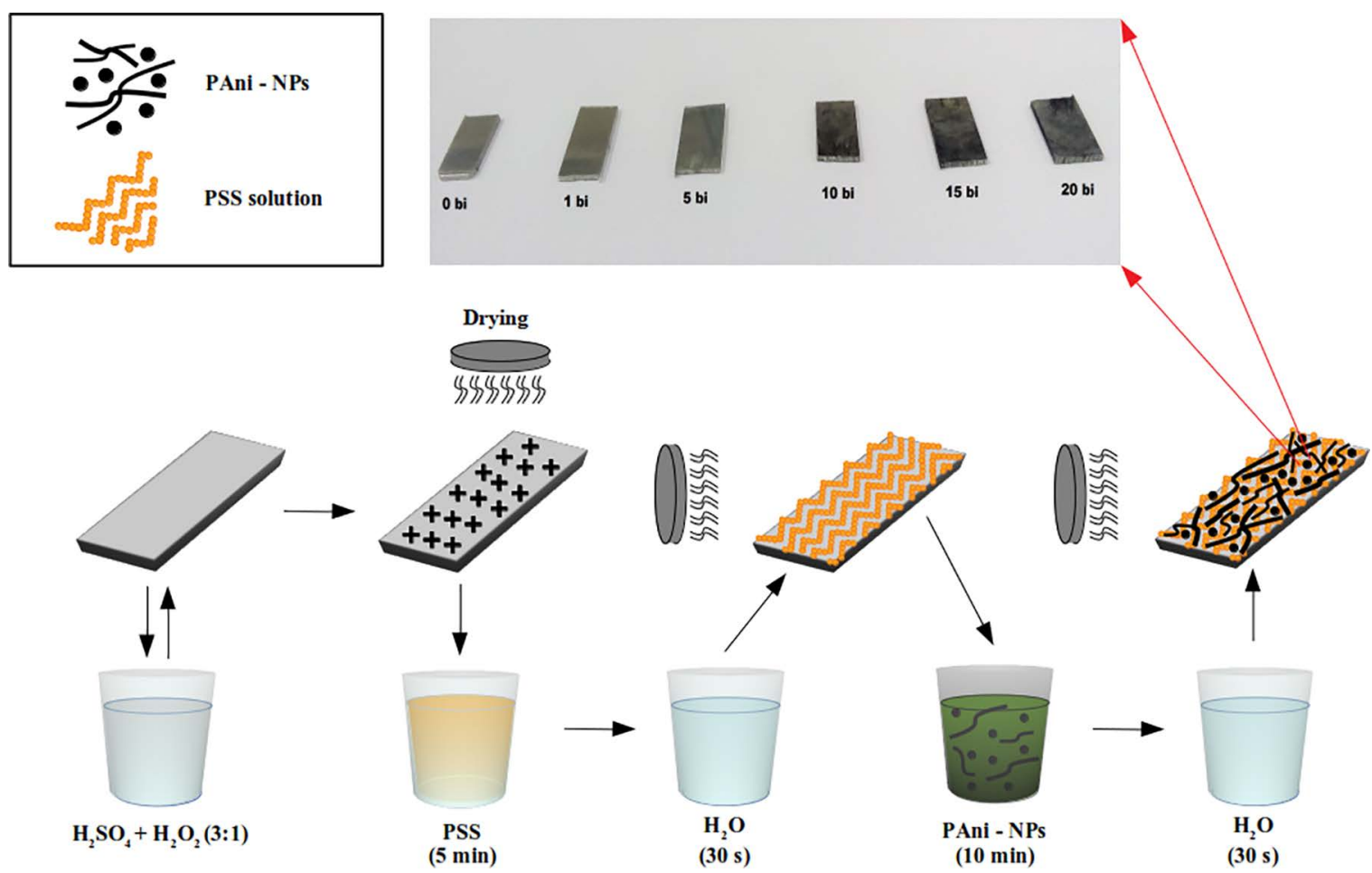

Figure 1. Schematic setup of PAni-NPs/PSS LbL film fabrication onto AA2524-T3 Al-alloy (top), followed by a digital photography of the film (geometric area of $1.0 \mathrm{~cm}^{2}$ ) with different number of bilayers (bottom). The drying process was carried out using nitrogen jet.

\subsection{Electrochemical tests}

The electrochemical characterizations were performed by open circuit potential (OCP) and potentiodynamic polarization curves $(\mathrm{PPc})$ in sodium chloride medium (0.6 mol L-1 $\mathrm{NaCl})$. A single-compartment electrochemical cell based on a typical three electrodes consisting of a work electrode (WE) of AA254-T3 alloy coated with PAni-NPs/ PSS film with $1 \mathrm{~cm}^{2}$ exposed area, a counter electrode of platinum (CE) and a reference electrode (RE) of silver chloride $(\mathrm{Ag} / \mathrm{AgCl} / 3 \mathrm{M} \mathrm{KCl})$ were used for the electrochemical tests. Data results were obtained by using an AutoLab $128 \mathrm{~N}$ potentiostat/galvanostat (Metrohm Autolab, Switzerland). The corrosion potential $\left(\mathrm{E}_{\text {corr }}\right)$ of the samples was monitored during $3600 \mathrm{~s}$. Regarding to the PPc tests, the measurements were made in the range of -1.4 to $-0.4 \mathrm{~V}$ with a potential sweep rate of $0.5 \mathrm{mV} \mathrm{s}^{-1}$.

\subsection{Micro abrasive wear tests (MAWTs)}

The MAWTs were performed using a fixed ball microwear device. A fixed frequency was set up of $80 \mathrm{rpm}$ with normal load of $0.5 \mathrm{~N}$ and test time of $3 \mathrm{~min}$. The MAWTs were realized in all samples (coated and uncoated) with no abrasive or lubricant liquid. After tests, all the samples were analysed by optical microscope Leica, model MC170 HD, with camera and software analysis, which was used to measure the diameters and the crater radio generated in a coated system by rotation of the ball. In this way, the volume of wear and coefficient of friction (COF) were determined. Figure 2 presents the microwear device used for the MAWTs. It is important to mention that the micro abrasive tests were carried out in triplicate in order to ensure a good reproducibility.

\section{Results and Discussion}

Figure 3 (a) presents the UV-Vis spectra of PAni-NPs/ PSS LbL films at different number of bilayers. It is possible to verify the presence of a broad band in the region of 190 to $355 \mathrm{~nm}$ due to the $\pi-\pi^{*}$ transition of the PSS aromatic ring. While the band extended between 350 and $510 \mathrm{~nm}$ may be corresponding to the transition $\pi-\pi^{*}$ in benzenoid rings and the transition $n-\pi^{*}$ in quinoid rings of PAni ${ }^{30-33}$. A linear growth of bilayers for PAni-NPs/PSS LbL films (Abs at $450 \mathrm{~nm}$ ) can be verified as shown in Figure 3 (b). The increase in absorbance with the number of bilayers is due to the growth associated with electrostatic interactions between sulfonate functional group $\left(\mathrm{SO}_{3}^{-}\right)$of PSS and amine groups $\left(\mathrm{NH}_{3}^{+}\right)$from PAni. Furthermore, the linear increase of the absorbance suggests that the amount of material deposited for each bilayer is proportional.

The characteristic of the Pure PAni, PAni-NPs/PSS film before and after corrosion tests were determined by using FTIR as shown in Figure 3 (c). In agreement with the literature ${ }^{34-37}$, a broad band around $3700-2500 \mathrm{~cm}^{-1}$ is assigned to an overlap of N-H stretching (secondary amine, from PAni) and 


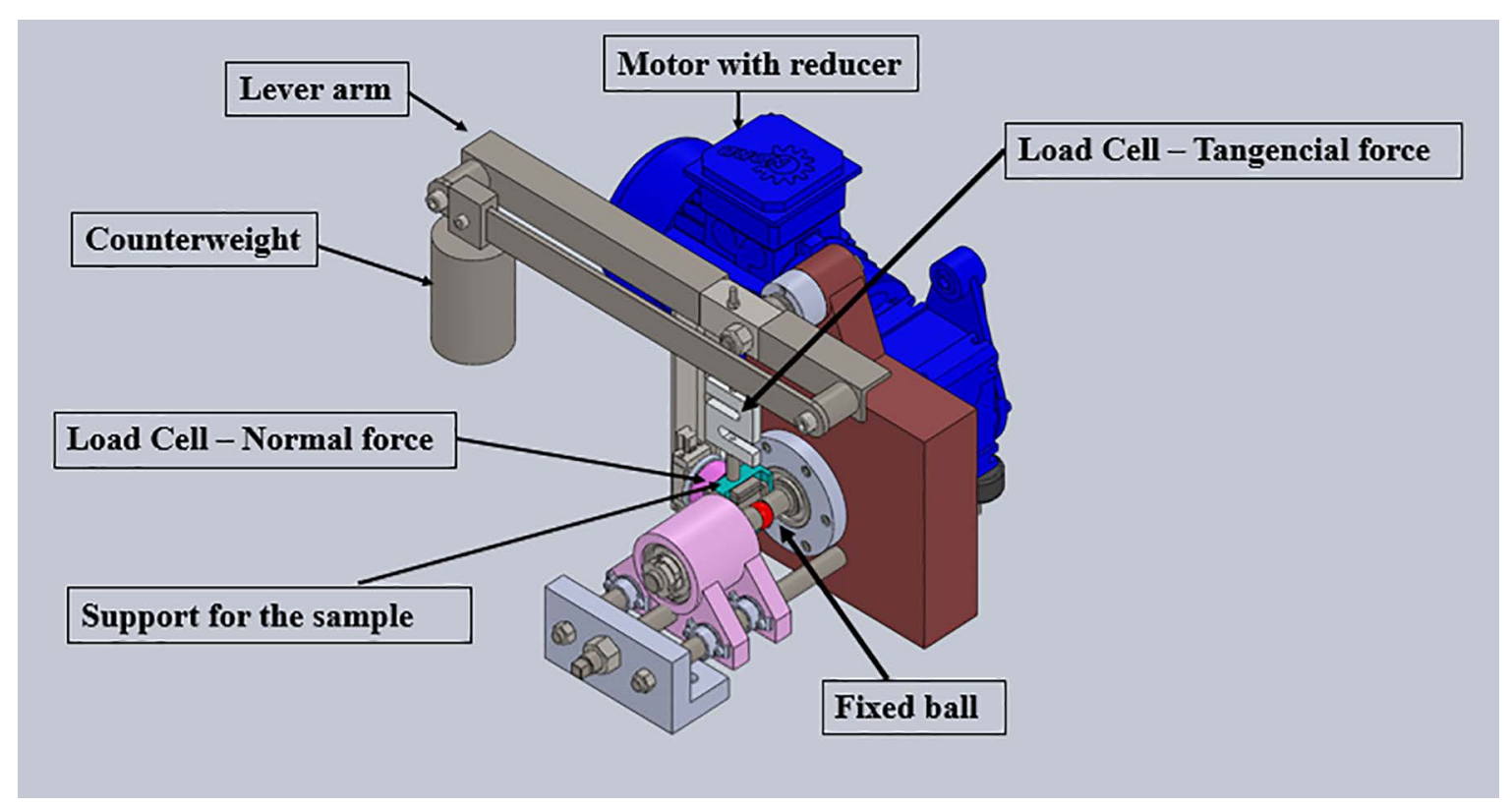

Figure 2. Schematic setup of the microwear device used for micro abrasive wear tests.

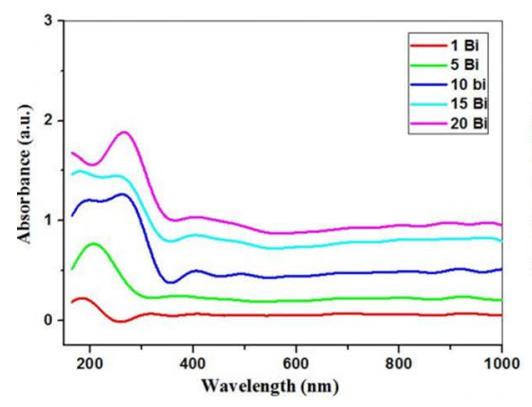

(a)

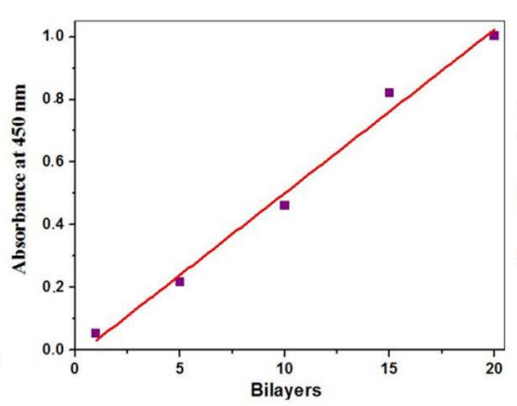

(b)

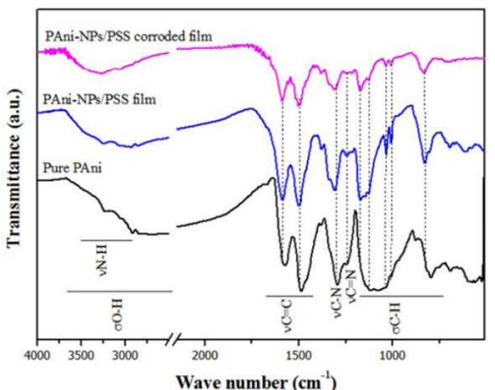

(c)

Figure 3. (a) UV-Vis spectra of PAni-NPs/PSS LbL films at different number of bilayers and (b) linear growth of bilayers for PAni-NPs/ PSS LbL films (Absorption of PAni at $450 \mathrm{~nm}$ ), (c) FTIR spectra of Pure PAni, PAni-NPs/PSS and PAni-NPs/PSS corroded film. The lines and dots are only guide for the eyes.

O-H deformation bands (adsorbed water). The FTIR spectra of Pure PAni also presents $\mathrm{C}=\mathrm{C}$ stretching bands at 1577 and $1485 \mathrm{~cm}^{-1}$ characteristic of benzene ring, the bands also referring to the secondary amine at 1300 and $1242 \mathrm{~cm}^{-1}$ are related to the $\mathrm{C}-\mathrm{N}$ and $\mathrm{C}=\mathrm{N}$ stretching modes, respectively, and bellow $1190 \mathrm{~cm}^{-1}$ there are some broad bands assigned to $\mathrm{C}-\mathrm{H}$ deformation in the benzene ring. The characteristics bands of $\mathrm{C}=\mathrm{C}, \mathrm{C}-\mathrm{N}$ stretching and $\mathrm{C}-\mathrm{H}$ deformation shift to lower modes $\sim 10 \mathrm{~cm}^{-1}$ in the PAni-NPs/PSS film before and after corrosion tests, in addition the relative intensity of $\mathrm{C}=\mathrm{N}$ stretching reduces considerably in the films, indicating a strong interaction between the Pure PAni and PSS film. On the other hand, there are no significant changes in the film spectra after corrosion testing. This latter indicates that the films are strongly incorporated onto the AA2524-T3 Alalloy, demonstrating that the LbL method may be propitious to form coating films resistant to corrosion.
In order to investigate the topography of the PAni-NPs/PSS on the surface of AA2524-T3 Al-alloy, AFM images over a scan $2.0 \times 2.0 \mu \mathrm{m}$ were verified, as can be seen in Figure 4. A rugged morphology characterized by risks from the mechanical cleaning of Al-alloy as well as different type of IMs ${ }^{12}$ prevenient from the solution heat treated and cold worked alloy process may be observed in all structures (Figure 4 (a)), resulting in an average rugosity of $5.98 \mathrm{~nm}$. With regarding to the coated Al-alloy (Figure 4 (b)) it is possible to observe that the presence of PAni-NPs are responsible for a considerable increase in the average rugosity $(\sim 31.33 \mathrm{~nm})$ in relation to the uncoated Al-alloy. The average diameter of PAni-NPs is about $36.00 \pm 1.73 \mathrm{~nm}$ and it was determined using a modular program for scanning probe microscopy (SPM) named as Gwyddion. The agglomerates identified in AFM images allow us to conclude that PAni-NPs were formed. In fact, the results obtained by AFM show that was a considerable 
modification on the surface of the coated Al-alloy by using PAni-NPs. The morphological study of the 2524-T3 Al-alloy surface containing PAni-NPs will help us to understand the corrosion and micro-abrasive processes as will be discussed in the following sections.

Figures 5 (a) and 5 (b) show the results of OCP and PPc of the AA2524-T3 Al-alloy containing different PAni-NPs/ PSS LbL films in $0.6 \mathrm{~mol} \mathrm{~L}^{-1}$ of $\mathrm{NaCl}$. The OCP curves show the dependence of potential with time is linked to the stochastic evolution of pitting events and to the resulting variations in the ratio of passive/active areas and/or cathode/ anode, which may be related to the presence of different types of IMs. The corrosion potential $\left(\mathrm{E}_{\text {corr }}\right)$ shifted to less negative values by increasing the number of bilayers. In addition, the pitting potential $\left(\mathrm{E}_{\mathrm{pit}}\right)$ values got shifted from $\sim-610 \mathrm{mV} \mathrm{SCE}$ for bare Al-alloy ${ }^{12}$ to $\sim-480 \mathrm{mV} \mathrm{SCE}$ for PAni-NPs/PSS coating. This shift of $130 \mathrm{mV}$ indicates that PAni-NPs/PSS films acted as a system of blocking aggressive species on the metal surface, protecting the substrate from the localized corrosion process. In other words, PAni was able to repair the defects present in the oxide layer and maintain its integrity and natural character of protection against the corrosion process. Figure 5 (c) confirm that even after the electrochemical tests there are regions on the surface of the AA2524-T3 A1-alloy that exhibit PAni-NPs/PSS films.

The results obtained in the present work, since using an alternative and more "structured" technique to obtain the PAni coating of the AA2524-T3 Al-alloy, corroborates the Zubillaga et al ${ }^{38}$, Bernhard ${ }^{39}$, Domingo et al $^{40}$ and Martins et $\mathrm{al}^{41}$. Zubillaga et $\mathrm{al}^{38}$, synthesized electrochemically anodic alumina films containing PAni and $\mathrm{TiO}_{2}$ or $\mathrm{ZrO}_{2}$ nanoparticles on the surface of AA2024-T3 alloy and verified the positive influence of the nanoparticulate system on the polarization curves in $5 \mathrm{mM} \mathrm{NaCl}$ and $0.1 \mathrm{~mol} \mathrm{~L}^{-1} \mathrm{Na}_{2} \mathrm{SO}_{4}$ solution. In a similar way to this work, the nanoparticle-containing coating of $\mathrm{TiO}_{2}$ acts as a barrier layer that blocks the pores of anodic alumina ${ }^{38}$. Bernhard ${ }^{39}$ deposited PAni electrochemically on the surface of stainless steel and verified an anodic form protection due to the PAni coating. Domingo et al ${ }^{40}$ prepared by electrodeposition of aniline, adherent PAni films on the 2024-T3 Al-alloy surface and suggested a decrease in the corrosion process protecting the alloy. Martins et al ${ }^{41}$, studied the production of PAni films on the AA6061-T6 Al-alloy used by aircraft industry by electropolymerization of aniline and reinforce the need for new coating systems that may replace bared in chromates, which have been classified as hazardous to environment and human health. The corrosion prevention of 2024-T3 aluminium alloy with a polyaniline/poly $(\gamma$-glyc idoxypropyltrimethoxysilane) bi-layer coating was studied by Mrad et al ${ }^{42}$. These authors showed that poly $(\gamma$-glyci doxypropyltrimethoxysilane, named as poly( $\gamma$-GPTMS) layer served as an effective barrier against the penetration of corrosive species and the results corroborate with those found in this work.

Figure 6 shows a comparison of the wear volume for the AA2524-T3 Al-alloy with and without PAni-NPs/PSS film. It can be noticed that both materials showed similar values of wear resistance. As reported by Cao et al ${ }^{26}$, the tribological performance of additive solids depends on the thickness of the film produced. In this work, possibly the small film thickness associated with its debris may have contributed to this similar result. Thus, it can be concluded that thin films do not act as tribofilms, while thick films function as abrasives. The coefficient of friction (COF) as a function of time for the material with and without coating is presented in Figure 7. It was observed that the COF of the AA2524-T3 alloy with PAni-NPs/PSS film reached a stationary state from the beginning of the test and the present peaks are due to the production of debris during the micro abrasive wear tests. The differentiated behavior in wear of the materials may be related to the modification of the mechanism acting in each condition. For the bare

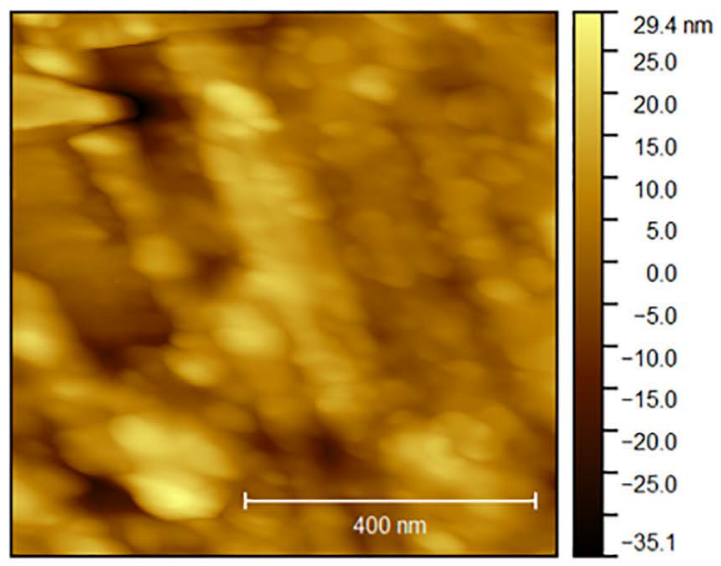

(a)

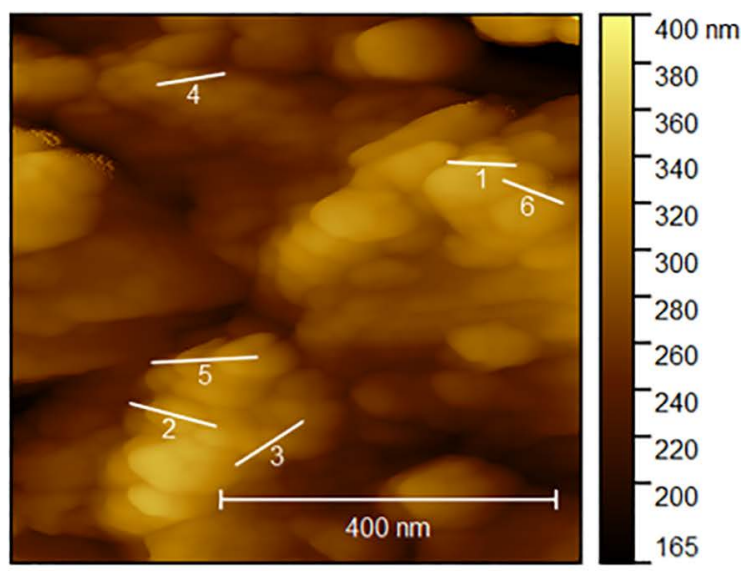

(b)

Figure 4. Top view AFM images at a 2.0 x $2.0 \mu \mathrm{m}$ scanned area, (a) uncoated AA2524-T3 Al-alloy and (b) PAni-NPs/PSS LbL films with 15 bilayers and the profile. 


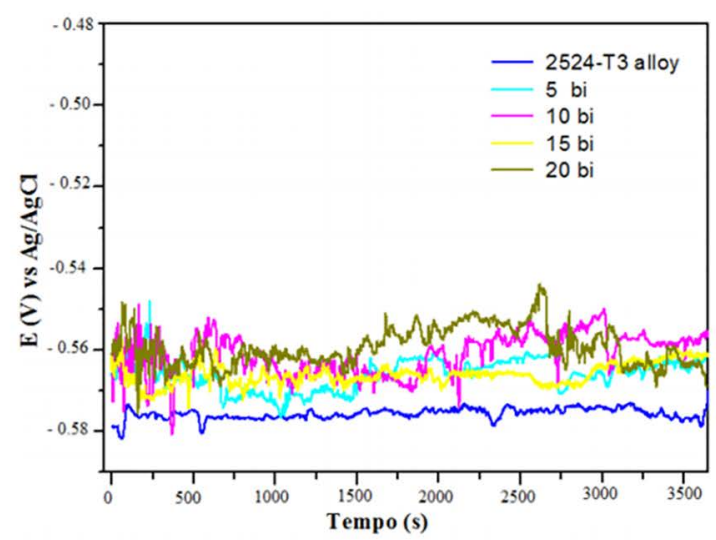

(a)

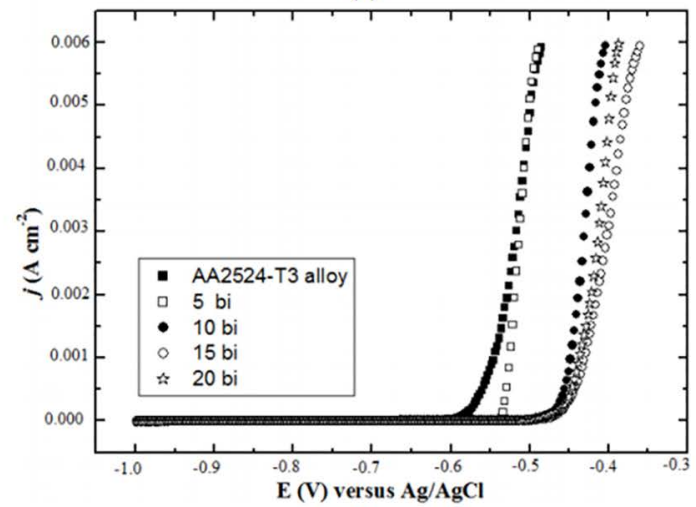

(b)
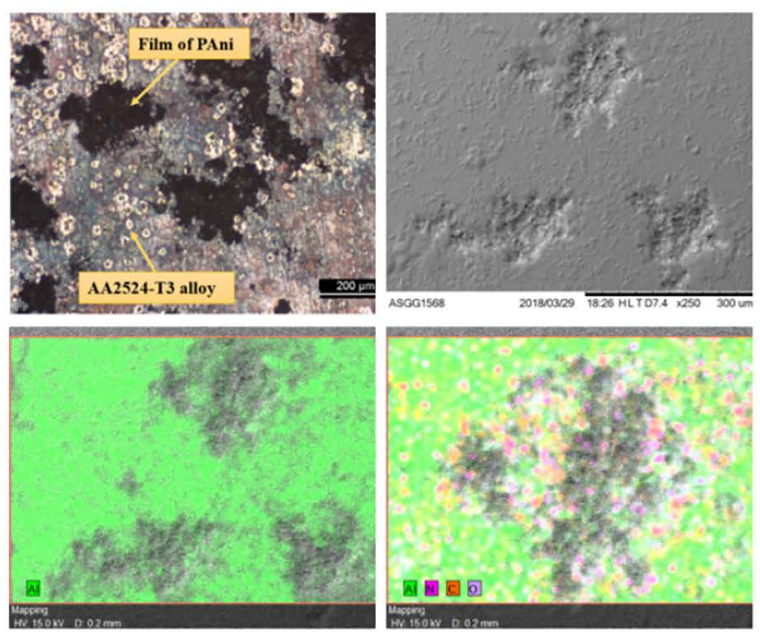

(c)

Figure 5. (a) OCP curves for the AA2524-T3 alloy in aerated $0.6 \mathrm{~mol} \mathrm{~L}^{-1}$ aqueous solution for a period of $3600 \mathrm{~s}$ of immersion, (b) PPc for the AA2524-T3 alloy in aerated $0.6 \mathrm{~mol} \mathrm{~L}^{-1} \mathrm{NaCl}$ aqueous solution at scan rate of $0.5 \mathrm{mV} \mathrm{s}^{-1}$, (c) images of surface alloy by optical microscopy and SEM in the pitting potential $\left(\mathrm{E}_{\mathrm{pit}}\right)$ for a 15 bilayer PAni-NPs/PSS film. EDX analysis confirms the presence of PAni-NPs/ PSS films on the surface of the AA2524-T3 alloy.

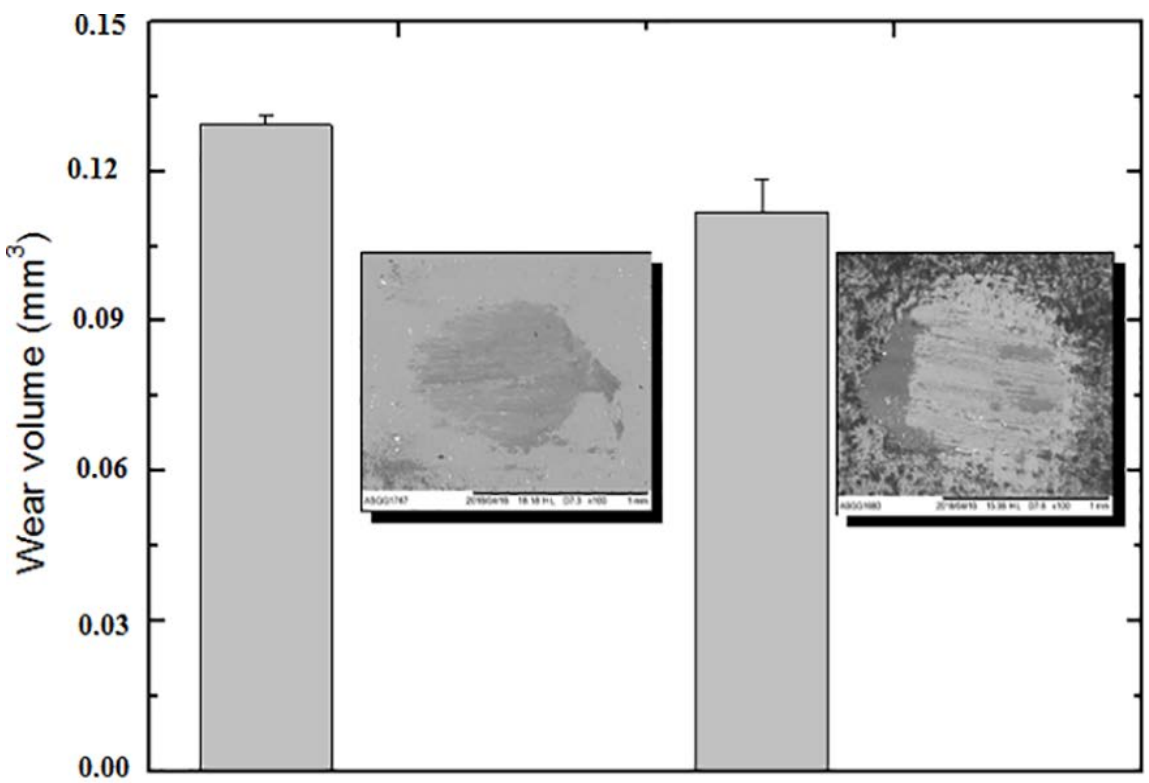

AA2524-T3

PAni-NPS/PSS Film

Figure 6. Wear volume for the AA2524-T3 alloy with and without PAni-NPs/PSS bilayers. 


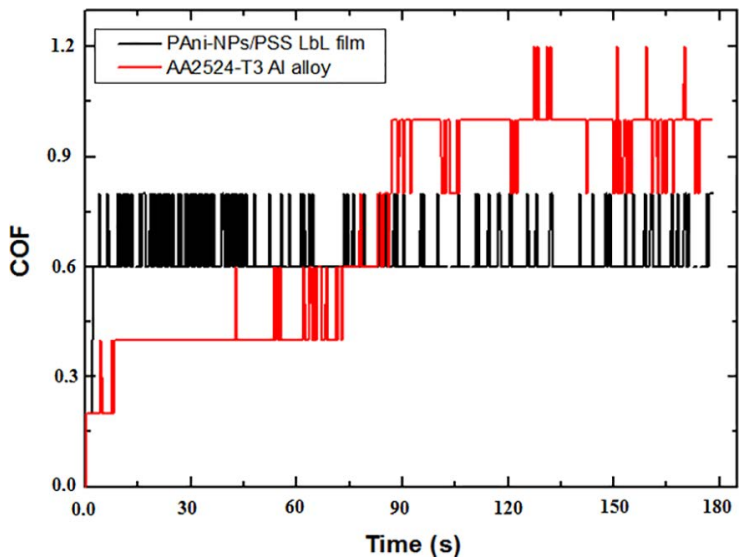

Figure 7. Coefficient of friction (COF) as a function of time for the material with and without coating. material, a low coefficient of initial friction is observed. This latter increases due to the production of the oxidized wear debris, increasing the severity of wear ${ }^{43}$. It should be emphasized that the high values of COF correspond to those related to the occurrence of abrasive wear by scratching ${ }^{44}$. The predominant wear mechanism for AA2524-T3 with PAni-NPs/PSS bilayers was scratching whereas for the bare material an equivalence between the scratching and rolling mechanisms was observed. These wear mechanisms can be verified through SEM images in figures 8 (a) and 8 (b).

Figure 8 (a) and 8 (b) show the micrographs of the AA2524-T3 alloy and the bare material coated with PAni-NPs/ PSS LbL after the micro abrasive wear tests, respectively. As can be verified in the images, the debris of the bare material became brittle and being hard, they fragment due to wear,
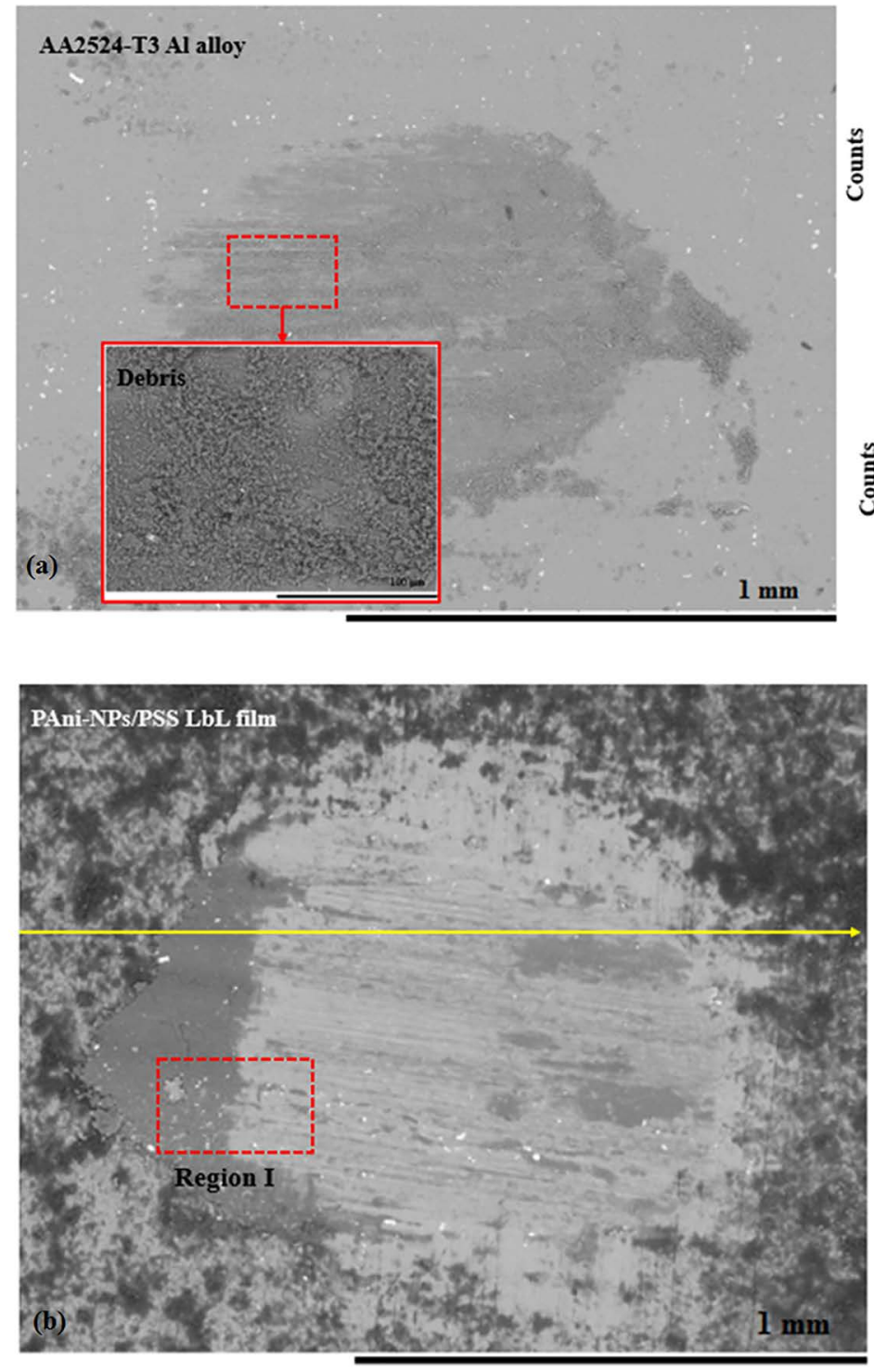
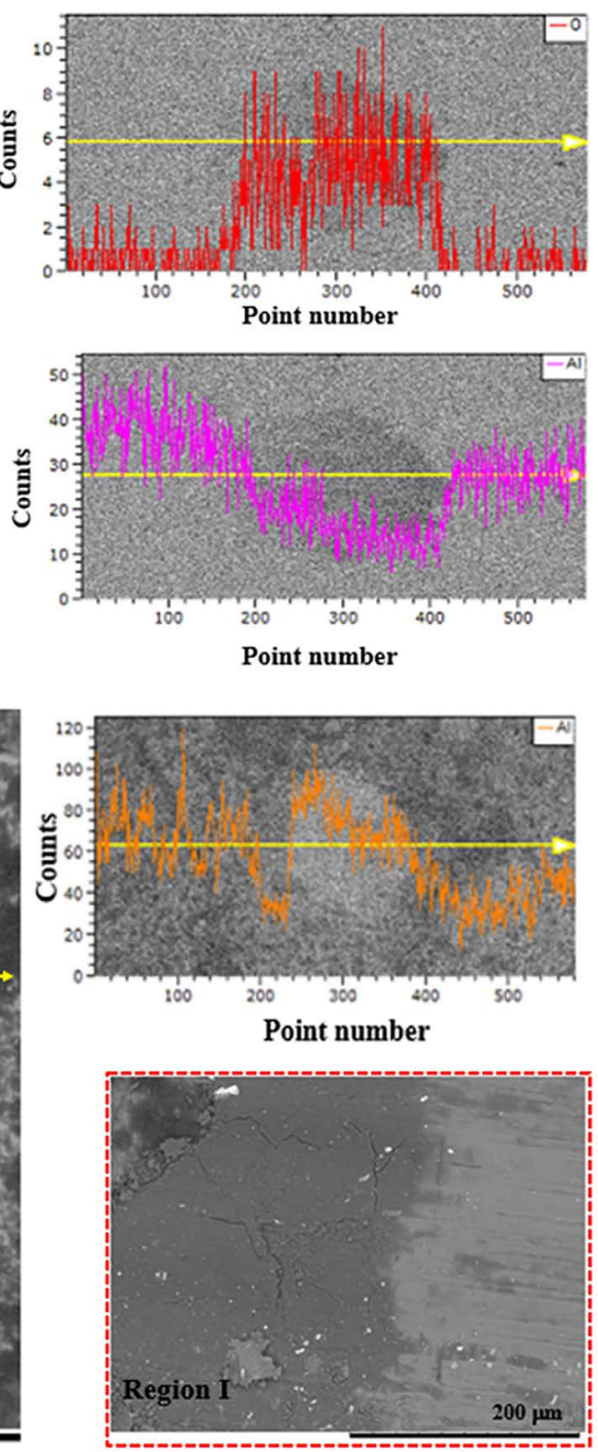

Figure 8. Micrographs of the (a) AA2524-T3 alloy and the (b) bare material coated with PAni-NPs/PSS LbL after the micro abrasive wear tests. 
this is characteristic of oxidized particles. With regarding to the AA2524-T3 alloy coated with PAni-NPs/PSS LbL film, the wear debris is exclusively the tearing of the film from the wear region, which is concentrated in the sample edge. By means of X-ray dispersive energy spectroscopy (EDX) technique, it was possible to verify that the wear region is rich in $\mathrm{Al}$ (bare material) and the region of concentration of debris is formed exclusively by the film removed from the surface (coated material).

\section{Conclusions}

The aim of this work was to study an alternative way to obtain PAni thin films on the surface of 2524-T3 Al-alloy using the LbL technique. The results demonstrated that the incorporation of the LbL method may be suitable as a coating against corrosion in aircraft materials. We can conclude in this work that 15 bilayers made the electrode more resistive and protected the material from the corrosion process. With regarding to micro abrasive wear tests, the predominant wear mechanism for AA2524-T3 with PAni-NPs/PSS bilayers was scratching whereas for the bare material an equivalence between the scratching and rolling mechanisms was observed. Based on these findings, we may prospect to explore new proof-of-concept approaches bared on LbL films for protective coatings in aircraft materials

\section{Acknowledgements}

The authors gratefully acknowledge the Federal University of São Carlos (UFSCar Sorocaba), Fatec Sorocaba, Federal University of Triângulo Mineiro (UFTM) for providing the laboratories facilities, as well as the National Counsel of Technological and Scientific Development (CNPq) (303684/2015-1 and 402142/2016-0), CAPES and FAPEMIG (APQ-02276-18) for the financial support.

\section{References}

1. Steglich D, Wafai H, Besson J. Interaction between anisotropic plastic deformation and damage evolution in $\mathrm{Al} 2198$ sheet metal. Engineering Fracture Mechanics. 2010;77(17):3501-3518.

2. ASM International. ASM Metals Handbook Volume 2: Properties and Selection: Nonferrous Alloys and Special-Purpose Materials. Materials Park: ASM International; 1990. p. 17-22.

3. Totten GE, Mackenzie DS, eds. Handbook of Aluminum: Volume 1: Physical Metallurgy and Process. Boca Raton: CRC Press; 2003.

4. Shen F, Yi D, Jiang Y, Wang B, Liu H, Tang C, et al. Semiquantitative evaluation of texture components and fatigue properties in 25244-T3 aluminum alloy sheets. Materials Science \& Engineering: A. 2016;657:15-25.

5. Bandeira RM, van Drunen J, Garcia AC, Tremiliosi-Filho G. Influence of the thickness and roughness of polyaniline coatings on corrosion protection of AA7075 aluminum alloy. Electrochimica Acta. 2017;240:215-224.

6. Costenaro H, Lanzutti A, Paint Y, Fedrizzi L, Terada M, de Melo $\mathrm{HG}$, et al. Corrosion resistance of $2524 \mathrm{Al}$ alloy anodized in tartaric-sulphuric acid at different voltages and protected with a TEOS-GPTMS hybrid sol-gel coating. Surface \& Coatings Technology. 2017;324:438-450.

7. Queiroz FM, Magnani M, Costa I, de Melo HG. Investigation of the corrosion behaviour of AA 2024-T3 in low concentrated chloride media. Corrosion Science. 2008;50(9):2646-2657.

8. de Bonfils-Lahovary ML, Laffont L, Blanc C. Characterization of intergranular corrosion defects in a $2024 \mathrm{~T} 351$ aluminium alloy. Corrosion Science. 2017;119:60-67.

9. Starke EA Jr., Staley JT. Application of modern aluminum alloys to aircraft. Progress in Aerospace Sciences. 1996;32(23):131-172.

10. Chen YQ, Pan SP, Zhou MZ, Yi DQ, Xu DZ, Xu YF. Effects of inclusions, grain boundaries and grain orientations on the fatigue crack initiation and propagation behaviour of 2524-T3 Al alloy. Materials Science \& Engineering: A. 2013;580:150158.

11. Gamboni OC, Moreto JA, Bonazzi LHC, Ruchert COFT, Bose Filho WW. Effect of salt-water fog on fatigue crack nucleation of Al and Al-Li alloys. Materials Research. 2014;17(1):250254.

12. Moreto JA, Marino CEB, Bose Filho WW, Rocha LA, Fernandes JSC. SVET, SKP and EIS study of the corrosion behaviour of high strength $\mathrm{Al}$ and $\mathrm{Al}-\mathrm{Li}$ alloys used in aircraft fabrication. Corrosion Science. 2014;84:30-41.

13. Moreto JA, Gamboni OC, Marino CEB, Bose Filho WW, Fernandes JCS, Rocha LA. Corrosion behaviour of Al and Al-Li alloys used as aircraft materials. Corrosão e Protecção de Materiais. 2012;31(3-4):60-64.

14. Moreto JA, Broday EE, Rossino LS, Quites FJ, Fernandes JCS, Bose Filho WW. Effect of Localized Corrosion on FatigueCrack Growth in 2524-T3 and 2198-T851 Aluminum Alloys Used as Aircraft Materials. Journal of Materials Engineering and Performance. 2018;27(4):1917-1926.

15. Moreto JA, Rossino LS, Bose Filho WW, Marino CEB, Ferreira MC, Taryba M, et al. On the Global and Localised Corrosion Behaviour of the AA2524-T3 Aluminium Alloy Used as Aircraft Fuselage Skin. Materials Research. 2019;22(2):e20180280.

16. Birbilis N, Buchheit RG. Electrochemical Characteristics of Intermetallic Phases in Aluminum Alloys: An Experimental Survey and Discussion. Journal of the Electrochemical Society. 2005;152(4):B140-B151.

17. Birbilis N, Cavanaugh MK, Buchheit RG. Electrochemical behavior and localized corrosion associated with $\mathrm{Al} 7 \mathrm{Cu} 2 \mathrm{Fe}$ particles in aluminum alloy 7075-T651. Corrosion Science. 2006;48(12):4202-4215.

18. Shi H, Tian Z, Hu T, Liu F, Han EH, Taryba M, et al. Simulating corrosion of $\mathrm{Al} 2 \mathrm{CuMg}$ phase by measuring ionic currents, chloride concentration and pH. Corrosion Science. 2014;88:178-186. 
19. Zhang W, Frankel GS. Transitions between pitting and intergranular corrosion in AA2024. Electrochimica Acta. 2003;48(9):11931210 .

20. Wloka J, Virtanen S. Detection of nanoscale $\eta-\mathrm{MgZn}_{2}$ phase dissolution from an $\mathrm{Al}-\mathrm{Zn}-\mathrm{Mg}-\mathrm{Cu}$ alloy by electrochemical microtransients. Surface and Interface Analysis. 2008;40(8):1219-1225.

21. Guillaumin V, Mankowski G. Localised corrosion of 2024 T351 aluminium alloy in chloride media. Corrosion Science. 1998;41(3):421-438.

22. Fontana A. Utilização de polianilina como revestimento protetor contra corrosão das ligas de alumínio 2014 F, 2024 T3 e 7075 $O$. [Dissertation]. São Carlos: Instituto de Química de São Carlos, Universidade de São Paulo; 2007.

23. Epstein AJ, Smallfield JAO, Guan H, Fahlman M. Corrosion protection of aluminum and aluminum alloys by polyanilines: A potentiodynamic and photoelectron spectroscopy study. Synthetic Metals. 1999;102(1-3):1374-1376.

24. Mrad M, Ben Amor Y, Dhouibi L, Montemor F. Electrochemical study of polyaniline coating electropolymerized onto AA2024-T3 aluminium alloy: Physical properties and anticorrosion performance. Synthetic Metals. 2017;234:145-153.

25. Fang J, Xu K, Zhu L, Zhou Z, Tang H. A study on mechanism of corrosion protection of polyaniline coating and its failure. Corrosion Science. 2007;49(11):4232-4242.

26. Cao Z, Xia Y, Chen C. Fabrication of novel ionic liquids-doped polyaniline as lubricant additive for anti-corrosion and tribological properties. Tribology International. 2018;120:416-454.

27. Gomes EC, Oliveira MAS. Corrosion protection by multilayer coating using layer-by-layer technique. Surface \& Coatings Technology. 2011;205(8-9):2857-2864.

28. Richardson JJ, Cui J, Bjo“rnmalm M, Braunger JA, Ejima H, Caruso F. Innovation in Layer-by-Layer Assembly. Chemical Reviews. 2016;116(23):14828-14867.

29. Cao Y, Andreatta A, Heeger AJ, Smith P. Influence of chemical polymerization conditions on the properties of polyaniline. Polymer. 1989;30(12):2305-2311.

30. Silverstein RM, Webster FX, Kiemle D, Bryce DL. Spectrometric Identification of Organic Compounds. Hoboken: John Wiley and Sons; 2005. p. 72-126.

31. Shimano JY, MacDiarmid AG. Polyaniline, a dynamic block copolymer: key to attaining its intrinsic conductivity? Synthetic Metals. 2001;123(2):251-262.

32. Domenech SC, Bortoluzzi JH, Soldi V, Franco CV, Gronski W, Radusch HJ. Characterization, morphology, thermal and mechanical properties of conductive polyaniline-functionalized EPDM elastomers obtained by casting. Journal of Polymer Science Part B: Polymer Physics. 2004;42(9):1767-1782.
33. Mattoso LHC. Polianilinas: síntese, estrutura e propriedades. Química Nova. 1996;19(4):388-399.

34. Lei Z, Zhao M, Dang L, An L, Lu M, Lo AY, et al. Structural evolution and electrocatalytic application of nitrogen-doped carbon shells synthesized by pyrolysis of near-monodisperse polyaniline nanospheres. Journal of Materials Chemistry. 2009;19(33):5985-5995.

35. Reddy KR, Sin BC, Ryu KS, Noh J, Lee Y. In situ self-organization of carbon black-polyaniline composites from nanospheres to nanorods: Synthesis, morphology, structure and electrical conductivity. Synthetic Metals. 2009;159(19-20):1934-1939.

36. Šeděnková I, Trchová M, Stejskal J. Thermal degradation of polyaniline films prepared in solutions of strong and weak acids and in water - FTIR and Raman spectroscopic studies. Polymer Degradation and Stability. 2008;93(12):2147-2157.

37. Zhang Z, Wei Z, Wan M. Nanostructures of Polyaniline Doped with Inorganic Acids. Macromolecules. 2002;35(15):59375942.

38. Zubillaga O, Cano FJ, Azkarate I, Imbuluzqueta G, Insausti M. Polyaniline and nanoparticle containing anodic films for corrosion protection of 2024T3 aluminium alloy. Transactions of the IMF. 2009;87(6):315-319.

39. Wessling B. Passivation of metals by coating with polyaniline: Corrosion Potential shift and morphological changes. Advanced Materials. 1994;6(3):226-228.

40. Huerta-Vilca D, Moraes SR, Motheo AJ. Electrosynthesized polyaniline for the corrosion protection of aluminum alloy 2024-T3. Journal of the Brazilian Chemical Society. 2003;14(1):52-58.

41. Martins NCT, Moura e Silva T, Fernandes JCS. Electrodeposition of polyaniline on aluminium alloy AA6061-T6: electrochemical activity and corrosion protection properties. In: Livro de Resumos das Jornadas de Electroquímica e Inovação; 2006 Out 20; Porto, Portugal. p. 23.

42. Mrad M, Amor YB, Dhouibi L, Montenor MF. Corrosion prevention of 2024-T3 aluminium alloy with a polyaniline/ poly $(\gamma$-glycidoxypropyltrimethoxysilane) bi-layer coating: Comparative study with polyaniline mono-layer feature. Surface \& Coatings Technology. 2018;337:1-11.

43. Lopes HSM, Moreto JA, Manfrinato MD, da Cruz NC, Rangel EC, Rossino LS. Micro Abrasive Behaviour Study of Carburization and Ion Plasma Nitriding of P20 Steel. Materials Research. 2016;19(3):686-694.

44. Cozza RC, Tanaka DK, Souza RM. Friction coefficient and abrasive wear modes in ball-cratering tests conducted at constant normal force and constant pressure-Preliminary results. Wear. 2009;267(1-4):61-70. 